\title{
Caregiving Self-efficacy and Knowledge Regarding Patient Positioning Among Malaysian Caregivers of Stroke Patients
}

Chai-Eng Tan ${ }^{1}$, May-Yin Hi ${ }^{1}$, Nur Sarah Azmi ${ }^{1}$, Nur Khairina Ishak ${ }^{1}$, Fathin alyaa Mohd Farid ${ }^{1}$, Aznida Firzah Abdul Aziz ${ }^{1}$

1. Department of Family Medicine, Faculty of Medicine, Universiti Kebangsaan Malaysia, Kuala Lumpur, MYS

Corresponding author: Chai-Eng Tan, tce@ppukm.ukm.edu.my

\section{Abstract \\ Background}

Most family caregivers of stroke patients in Malaysia do not receive adequate prior preparation or training. This study aimed to determine levels of patient positioning knowledge and caregiving self-efficacy among caregivers of stroke patients.

\section{Methods}

This cross-sectional study was conducted at an urban teaching hospital involving 128 caregivers of stroke patients. The caregivers were conveniently sampled and completed the data collection forms, which comprised their socio-demographic data, patients' functional status, the Caregiving Knowledge For Stroke Questionnaire: Patient Positioning (CKQ-My@ Patient Positioning) to measure caregiver's knowledge on patient positioning, and the Family Caregiver Activation Tool (FCAT@) to measure caregivers' self-efficacy in managing the patient. Descriptive and multivariate inferential statistics were used for data analysis.

\section{Results}

Among the caregivers sampled, $87.3 \%$ had poor knowledge of positioning (mean score $14.9 \pm 4.32$ ). The mean score for FCAT was $49.7 \pm 6.0$ from a scale of 10 to 60 . There was no significant association between knowledge on positioning and self-efficacy. Multiple linear regression showed that caregivers' age $(\mathrm{B}=$ $0.146, p=0.003)$ and caregiver training $(B=3.302, p=0.007)$ were independently associated with caregivers' self-efficacy.

\section{Conclusion}

Caregivers' knowledge on the positioning of stroke patients was poor, despite a fairly good level of selfefficacy. Older caregivers and receiving caregiver training were independently associated with better

Received 02/25/2020 Review began 02/29/2020 Review ended 03/20/2020 Published 03/24/2020

๑) Copyright 2020

Tan et al. This is an open access article distributed under the terms of the Creative Commons Attribution License CC-BY 4.0., which permits unrestricted use, distribution, and reproduction in any medium, provided the original author and source are credited. caregiver self-efficacy. This supports the provision of caregiver training to improve caregiver self-efficacy.

Categories: Family/General Practice, Physical Medicine \& Rehabilitation, Other

Keywords: stroke, caregiver, self-efficacy, knowledge, caregiver education, home care, nursing

\section{Introduction}

When a stroke survivor develops long-term disability, the role of caregivers is of utmost importance in the rehabilitation and nursing care of the patient. The majority of stroke caregivers in Malaysia are informal caregivers, comprising family members of the patients [1-2]. Very few Malaysian families can afford paid caregivers, whether trained or untrained [1]. Family caregivers shoulder the responsibilities of providing direct care, emotional support, coordinating care, financial support, and advocacy for the patient [3].

Caregivers need basic caregiving knowledge and skills to care for stroke patients in view of the various disabilities and potential complications of the stroke. These include performing or aiding the patients in basic activities of daily living such as feeding, mobilizing, toileting, bathing, and dressing. They also require higher-level skills such as supervision and administration of medications, handling medical equipment (e.g. dressing, regular turning), managing the healthcare system (appointments, refilling prescriptions), arranging transportation, and being the patient's advocate [4].

The prevalence of caregiver burden ranged from $25 \%$ to $54 \%$ worldwide [5]. Informal caregivers have been found to have a higher prevalence of depression, as well as the negative effects of their physical, psychological, and social health [6]. In Malaysia, stroke caregivers also face unmet needs in terms of information regarding problem-solving and medical-related knowledge, financial, and social support [2]. The burden faced by caregivers has been associated with various negative impact toward patients' well- 
being, such as increased post-stroke depression, cognitive decline, physical disability, and general quality of life [7-9].

Caregiver training may reduce the burden and improve caregivers' quality of life and confidence in providing care to the patient [10-12]. The provision of information alone has been shown to improve caregivers' knowledge and satisfaction [13]. In various developed countries, transition care programs have been developed to meet the need for caregiver training and support [14-15]. During the transition process, structured caregiver training and post-discharge support and follow-up are provided to ensure patient and caregiver safety. The implementation of transition care is highly variable as they are tailored to the available social and community health services at respective locations.

In Malaysia, most health facilities have yet to implement structured caregiver training for caregivers of stroke patients [16]. There are limited studies regarding the unmet needs of caregivers of stroke patients. A study conducted among informal caregivers in the Klang Valley showed that $78 \%$ wanted to have more information to solve their problems, as well as $67 \%$ who wanted more information and advice from medical specialists [2]. This suggests most Malaysian informal caregivers have low caregiving knowledge. Caregivers need basic caregiving knowledge such as patient positioning, feeding, patient transfer, and pressure ulcer prevention to prevent complications or adverse events both to patients and caregivers alike [17]. Caregiver training may also help improve the self-efficacy of caregivers, reduce anxiety in providing care, prevent caregiver burnout, and promote better outcomes and quality of life for the stroke patient $[10,18]$.

To date, there are no local studies that measure knowledge specific to caregiving for stroke patients. Hence, this study aims to determine the level of caregiving knowledge among caregivers and their level of confidence in caring for stroke patients.

\section{Materials And Methods}

This cross-sectional study was conducted at an urban teaching hospital from February 2017 to October 2017. The study population involved adult caregivers (aged 18 years and above) of stroke patients who had been diagnosed for more than 3 months and attending rehabilitation activities at the department. Both primary and secondary caregivers were eligible for study inclusion. The respondents were conveniently sampled in the waiting area of the rehabilitation department. Only Malaysian caregivers who were able to understand English or Malay were recruited. Paid formal caregivers and family caregivers for the institutionalized patients were excluded from the study.

The sample size was calculated to determine the population mean, using Yamane's formula for a population of 188 patients who attend rehabilitation sessions over 6 months with an error tolerance of 0.05 [19]. A minimum sample size of 128 patients was required for this study.

Data was collected using an interviewer-assisted questionnaire consisting of 4 sections: 1 ) sociodemographic data of the caregiver; 2) caregiving profile; and 3) Caregiving Knowledge Questionnaire (CKQ-My@: Patient Positioning) and Family Caregiving Activation Transitions (FCAT). Interviewers assisted in reading out the items and filling in their responses.

\section{Study tools}

The CKQ-My@ was a validated bilingual questionnaire that measured caregiving knowledge with 2 subscales: positioning and feeding [20]. The positioning subscale (CKQMy-Positioning) had 28 items where respondents were required to indicate which pictures of patient positioning were correct. The positioning subscale showed good internal consistency reliability (Cronbach alpha 0.70 ). The cut-off score for good knowledge was arbitrarily set at 20 for positioning subscale, based on the mean score from the pilot study [20]. This cut-off score was applied because the pilot study was conducted on a population similar to the current study. The feeding subscale was not used for this analysis in view that it was too easy for most caregivers.

The FCAT was used to determine the caregivers' level of self-efficacy for performing several generic tasks related to the care of a patient with chronic diseases [21]. These tasks included managing patient medications, appointments, care plan, and awareness of where to obtain relevant medical information. The possible range of scores for the FCAT was from 6 to 60. The 10-item FCAT was translated and underwent face validation and pilot testing. The translated FCAT had good internal consistency reliability (Cronbach alpha 0.78) from the pilot study [20]. Higher FCAT scores demonstrated better self-efficacy in caring for the patients. There is no cut-off score to categorize respondents with good or poor self-efficacy in caregiving.

\section{Data analysis}

Data were analyzed using IBM SPSS Statistics Version 25. Descriptive data were described using frequencies, percentages, means, standard deviations, medians, and interquartile ranges. Multiple linear regression was used to determine the association between the FCAT scores and the caregivers' sociodemographic and caregiving characteristics. All independent variables with clinical significance were entered into the model 


\section{Cureus}

for multiple linear regression. The independent variables were checked to ensure normality of residuals and absence of collinearity, to fulfill assumptions required to conduct multiple linear regression. Independent variables that were found to violate the assumptions were examined and removed from the model where appropriate. Alpha was set at 0.05 for statistical significance.

\section{Ethical approval}

This study received ethical approval from the UKMMC Medical Research and Ethics Committee (FF-2017196). Permission to translate and adapt the CKQ-My and FCAT were obtained from the original developers of the questionnaire. Caregivers received verbal and printed brief information about the study and provided written consent prior to their participation. All data were kept confidential and only accessible to the research team members.

\section{Results}

A total of 128 caregivers were included in this study. The mean age of our study sample was $45.8 \pm 16.81$ years. Most caregivers were female $(64.8 \%, \mathrm{n}=83)$, Malay $(64.8 \%, \mathrm{n}=83)$, married $(66.4 \%, \mathrm{n}=85)$, had up to secondary level education $(62.5 \%, \mathrm{n}=80)$ and represented the middle income group $(50.8 \%, \mathrm{n}=65)$. Most of them $(60.2 \%, \mathrm{n}=77)$ were primary caregivers and majority $(75.8 \%, \mathrm{n}=97)$ reported that they did not receive any training. More than half of the caregivers surveyed were caring for severely dependent patients, with a modified Rankin score (MRS) of 4-5 ( $n=69,54 \%)$. About $72.6 \%(n=94)$ of caregivers surveyed had been caring for patients who had been diagnosed with stroke for less than 5 years. Table 1 displays the characteristics of our respondents.

Gender

Female

Race

Malay

Chinese

Others

Marital status

Single

Married

85 (66.4)

Divorced/Widowed

Education

Primary level

Secondary level

Tertiary level

Household income

$<$ RM1000

RM1000 - RM4999

>RM5000

Role

Primary caregiver

Secondary caregiver

$51(39.8)$

Duration of diagnosis

$0-5$ years

94 (72.6) 


\section{Cureus}
$6-10$ years
$24(18.8)$
$>10$ years
$11(8.6)$
Modified Rankin Score (MRS)
Independent to moderately dependent (MRS 1 - 3)
Severely dependent to totally dependent (MRS 4 -5)
$69(54)$
Received caregiver training
Yes
$31(24.2)$
No
$97(75.8)$
Information source
Doctors
Nurses
Internet or other informal source
$24(18.8)$
Other hospital personnel
Other caregivers
Books or other formal sources
Non-governmental organisations
Others
$8(6.3)$

\section{TABLE 1: Background characteristics of respondents}

The mean knowledge score for patient positioning was $14.5 \pm 4.22$ (Table 2). The majority of caregivers (85.9\%) had poor knowledge of positioning.

Knowledge for positioning (Range of scores 0-29)

Poor knowledge $(<20)$

Good knowledge (>20)

Mean score (sd)

Median score (IQR)

\section{n (\%)}

110(85.9)

$18(14.1)$

$14.5( \pm 4.22)$

$14(11,18)$

\section{TABLE 2: Knowledge scores for patient positioning}

sd, standard deviation; IQR, interquartile range

The mean score for FCAT was 49.7 \pm 6.0$)$ and shown in Table 3. While there are no local population norms to define the cut off scores for high or low self-efficacy, the mean FCAT score appeared to be at the higher range of scores, suggesting good self-efficacy. Positioning knowledge was not correlated with the caregivers' selfefficacy $(r=0.046, p=0.607)$. 


\section{Cureus}

\section{FCAT Score}

Total FCAT Score (Range of scores 10-60)

I am able to make sure he/she goes to every scheduled medical appointment.

I know when, how much, and how his/her medications should be taken.

If he/she needs help from a healthcare professional, I am confident I can insist until I get what is needed.

I maintain an accurate list of his/her medications.

I have or will check with the doctor to make sure which medications he/she should be taking (including how often and how much)

I understand which tasks in his/her care plan that should be prioritized.

I make sure a written list of questions is taken along with him/her to every medical appointments.

I have a trusted healthcare personnel whom I can contact if I have questions about medications.

I know the signs that show his/her condition is getting worse and how to respond.

I keep a written record of his/her health conditions, allergies, medications, along with the names and phone numbers of treating health professionals.
Mean

Median

(sd)

(IQR)

$49.7(6.0)$

$50(46$,

53.8)

$5.51(0.70) \quad 6(1)$

5.26

(0.92) $6(1)$

5.24

(0.79)

5 (1)

5.23

(0.96)

5 (1)

5.16

(1.02)

5 (1)

4.95

(0.93)

\section{TABLE 3: Caregiving self-efficacy scores}

FCAT, Family Caregiver Activation in Transitions; IQR, interquartile range; sd, standard deviation

Multiple linear regression analysis was done to identify independent associations between the FCAT scores with independent variables such as caregivers' age, gender, race, education, income, caregiver status, caregiver training, duration of care, knowledge score in positioning and patients' modified Rankin score (Table 4). 


\section{Cureus}

\begin{tabular}{|c|c|c|c|c|c|}
\hline Independent variables & Unstandardized coefficient, B & Standard error & Standardized coefficient, $\beta$ & $\mathbf{t}$ & $\mathbf{p}$ \\
\hline Constant & 41.181 & 3.376 & & 12.198 & $<0.001$ \\
\hline Age & 0.146 & 0.48 & 0.406 & 3.06 & $0.003^{\star}>>>>$ \\
\hline Married & -0.863 & 1.189 & -0.080 & -0.726 & 0.469 \\
\hline Secondary education & -0.014 & 1.378 & -0.001 & -0.010 & 0.992 \\
\hline Tertiary education & -1.136 & 1.532 & -0.084 & -0.741 & 0.460 \\
\hline Middle income & 2.272 & 1.387 & 0.151 & 1.639 & 0.104 \\
\hline High income & -0.353 & 2.962 & -0.010 & -0.119 & 0.905 \\
\hline Primary caregiver & -0.682 & 1.284 & -0.055 & -0.531 & 0.596 \\
\hline Received caregiver training & 3.302 & 1.205 & 0.236 & 2.741 & $0.007^{*}>>>>$ \\
\hline Patient's MRS & -0.164 & 0.431 & -0.033 & -0.380 & 0.704 \\
\hline Duration of caregiving & 0.075 & 0.120 & 0.055 & 0.623 & 0.535 \\
\hline Position knowledge score & 0.222 & 0.129 & 0.154 & 1.719 & 0.088 \\
\hline
\end{tabular}

TABLE 4: Multiple linear regression for independent associations with FCAT scores

${ }^{*} \mathrm{p}<0.05$; FCAT, family caregiver activation tool; MRS, Modified Rankin Score

The regression equation was significant $(F=2.777(11,114), \mathrm{p}=0.003)$, with $\mathrm{R} 2$ of 0.211 . The caregiver's predicted FCAT score was $41.18+0.146$ (Age) -0.863 (Married) - 0.014 (Secondary education) - 1.136 (tertiary education) +2.27 (middle income) -0.353 (high income) -0.682 (primary caregiver) +3.302 (Caregiver training) - 0.162 (Modified Rankin Score) + 0.075 (duration of caregiving) + 0.222 (Positioning knowledge) Only age and caregiver training had a significant linear relationship with the FCAT score. The FCAT score increased by 0.146 for every year of age and by 3.32 with caregiver training.

\section{Discussion}

The findings of this study highlighted the deficiencies of informal stroke caregivers' knowledge about patient positioning. This appeared to contrast with their perceived self-efficacy in caring for stroke patients. The descriptive analyses also show differences in their self-efficacy for various caregiving tasks.

Stroke patients, particularly those with hemiparesis, are at increased risk of developing complications such as pressure injuries and contractures. Correct positioning after a stroke is an essential component of rehabilitation therapy, as it can help to prevent these complications [22]. Correct positioning can also promote optimal recovery by modulating the muscle tone, ensure stability and enhance comfort [22]. Unfortunately, with the large amount of information related to the stroke itself, caregivers might not have been educated regarding the importance of proper positioning methods. Again, patient positioning is not routinely taught in Malaysian hospitals before the patient is discharged home. To date, there are no published papers reporting on the discharge planning process for stroke patients in Malaysia. The Malaysian clinical practice guidelines on the management of ischemic stroke do not include recommendations on caregiver training [23]. It only includes “assessment of patient's suitability for rehabilitation" as one of the clinical audit indicators for stroke services.

As the CKQ-My@ is the first validated tool in Malaysia to measure stroke caregivers' knowledge of positioning, there are no equivalent studies for direct comparison. A study among formal caregivers in Korea found that $64.3 \%$ of responses regarding positioning were correct [24]. This is a stark contrast from the $85.9 \%$ of caregivers with poor knowledge (CKQ-My score of $<20$ ) in this study. While the Korean study did not use a validated scoring scale, this still suggests possible differences for knowledge between their population and our study population. However, the Korean caregivers were those who had received training and formally employed to care for stroke patients in various healthcare institutions in Korea. Awareness regarding the importance of proper positioning for stroke patients was also suboptimal among healthcare professionals in Singapore [25]. This suggests that healthcare professionals need to recognize the importance of proper positioning for stroke patients in order to train caregivers before the patients are discharged. 
The FCAT scores represent the self-efficacy of stroke caregivers, where higher scores indicate better selfefficacy. However, the FCAT items do not ask about direct caregiving tasks such as patient positioning. Instead, it asks about their ability to supervise and execute the care plans for the patient, including appointments, medications, and consultations with healthcare professionals. The caregiver's age and having caregiver training were significantly associated with better self-efficacy. However, the effect of age on the self-efficacy was small. A similar effect of age on caregivers of patients in dementia has been observed [26]. Younger caregivers were at higher risk for burnout [12].

The provision of caregiver training helped to improve the self-efficacy of stroke caregivers, which is supported by various caregiver training interventions [10,27]. This is important as better caregiver selfefficacy has been shown to improve stroke patient's recovery and mental health status [28-29]. Better caregiver self-efficacy also helps to mediate caregiver burden, improve perceived social support and mental well-being [30]. Hence, a structured caregiver training programme in Malaysia is strongly needed to provide support for caregivers. The contents of caregiver training should include knowledge on patient positioning, understanding the patient's care plan, managing the patient's health records and knowing what red flag signs to watch out for.

This study is one of the few studies on caregivers of stroke patients in Malaysia. It gives insight into the knowledge and self-efficacy of caregivers in managing stroke patients at home. The findings provide some insight as to possible content for developing caregiver training programmes. The instrument for measuring caregiver knowledge had content, face, and construct validity [20]. The FCAT had content, linguistic and face validity, as well as good internal consistency reliability. Using multiple linear regression analysis provided a way to statistically adjust for potential confounders to determine the independent associations between FCAT scores with each independent variable.

However, it is limited by the lack of generalizability to the Malaysian population due to convenience sampling and only included caregivers of stroke patients at one single urban teaching hospital. Hence some selectional bias may be present and the results should be interpreted with caution. The results may not be extrapolated to caregivers residing in other regions of Malaysia.

\section{Conclusions}

In conclusion, caregivers of stroke patients in this study had poor knowledge of patient positioning. The self-efficacy of caregivers were influenced by their age as well as provision of caregiver training. We recommend more studies on the unmet needs for caregivers of stroke patients to be conducted locally. The findings will then be translated into development of caregiver training programmes and policy in ensuring that it is conducted throughout hospitals in Malaysia.

\section{Appendices}




\section{Cureus}

Pengetahuan Jagaan Pesakit Strok (CKQ-My@) - Posisi pesakit Caregiving Knowledge For Stroke Patients Questionnaire (CKQ-My(Q) - Patient positioning

Berikut merupakan penerangan mengenai kedudukan pesakit di atas katil. Sila pilih jawapan yang betul dengan menandakan $v$ di ruangan kosong. Anda boleh memilih lebih daripada satu jawapan betul bagi setiap bahagian.

The following pictures show various positions of a stroke patient in bed. Please select the correct positioning by marking $\sqrt{ }$ in the blanks. You may select more than one correct answer for each section.

\section{Berbaring menghadap ke atas Lying straight facing up}

Tapak kaki (feet)
1a. Biarkan tapak kaki dalam keadaan yang selesa.
1a. Leave the feet in a naturally comfortable position.
(Answer)

\section{FIGURE 1: Sample page for CKQ-My Positioning}

For permissions, please contact Dr Chai-Eng Tan at tce@ppukm.ukm.edu.my

\section{Additional Information}

\section{Disclosures}

Human subjects: Consent was obtained by all participants in this study. Universiti Kebangsaan Malaysia Medical Research and Ethics Committee issued approval FF-2017-196. This study received ethical approval from UKMMC Medical Research Ethics Committee (FF-2017-196). . Animal subjects: All authors have confirmed that this study did not involve animal subjects or tissue. Conflicts of interest: In compliance with the ICMJE uniform disclosure form, all authors declare the following: Payment/services info: All authors have declared that no financial support was received from any organization for the submitted work. Financial relationships: All authors have declared that they have no financial relationships at present or within the previous three years with any organizations that might have an interest in the submitted work. Intellectual property info: Caregiving Knowledge for Stroke Questionnaire: Patient Positioning tool is a validated tool for which copyright belongs to all authors. Family Caregiving Activation Transitions tool is the copyright of Dr Eric Coleman. Other relationships: All authors have declared that there are no other relationships or activities that could appear to have influenced the submitted work.

\section{Acknowledgements}

We thank the Department of Rehabilitation Medicine Service of UKMMC for permission to collect data, Dr $\mathrm{Su}$-Jin Choi for permission to adapt the caregiver's knowledge survey, as well as Prof Dr Eric Coleman for 
permission to use and translate the FCAT for this study. This study received ethical approval from UKMMC Medical Research Ethics Committee (FF-2017-196) and is self-funded.

\section{References}

1. Goh ZY, Lai MM, Lau SH, et al.: The formal and informal long-term caregiving for the elderly: the Malaysian experience. Asian Soc Sci. 2013, 9:174-184. 10.5539/ass.v9n4p174

2. Abu Bakar SH, Weatherley R, Omar N, et al.: Projecting social support needs of informal caregivers in Malaysia. Heal Soc Care Community. 2014, 22:144-154. 10.1111/hsc.12070

3. Gibson MJ, Kelly K, Kaplan AK: Family Caregiving and Transitional Care: A Critical Review . National Center on Caregiving, Family Caregiver Alliance, San Francisco, CA; 2012.

4. Given B, Sherwood PR, Given CW: What knowledge and skills do caregivers need? . Am J Nurs. 2008, 108:2834. 10.5175/JSWE.2008.773247703

5. Rigby H, Gubitz G, Phillips S: A systematic review of caregiver burden following stroke . Int J Stroke. 2009, 4:285-292. 10.1111/j.1747-4949.2009.00289.x

6. Han B, Haley WE: Family caregiving for patients with stroke. Stroke. 1999, 30:1478-1485. 10.1161/01.str.30.7.1478

7. Suh M, Kim K, Kim I, et al.: Caregiver's burden, depression and support as predictors of post-stroke depression: a cross-sectional survey. Int J Nurs Stud. 2005, 611:618. 10.1016/j.ijnurstu.2004.10.002

8. Othman Z, Wong ST, Drahman I, et al.: Caregiver burden is associated with cognitive decline and physical disability of elderly post-stroke patients. Middle-East J Sci Res. 2014, 22:1265-1271. 10.5829/idosi.mejsr.2014.22.09.9216

9. Ogunlana MO, Dada OO, Oyewo OS, et al.: Quality of life and burden of informal caregivers of stroke survivors. Hong Kong Physiother J. 2014, 32:6-12. 10.1016/j.hkpj.2013.11.003

10. McCullagh E, Brigstocke G, Donaldson N, et al.: Determinants of caregiving burden and quality of life in caregivers of stroke patients. Stroke. 2005, 36:2181-2186. 10.1161/01.STR.0000181755.23914.53

11. Silver HJ, Wellman NS: Family caregiver training is needed to improve outcomes for older adults using home care technologies. J Am Diet Assoc. 2002, 102:831-836. 10.1016/S0002-8223(02)90185-9

12. van den Heuvel ETTP, De Witte LP, Schure LMLM, et al.: Risk factors for burn-out in caregivers of stroke patients, and possibilities for intervention. Clin Rehabil. 2001, 15:669-677. 10.1191/0269215501cr446oa

13. Smith J, Forster A, Young J: Cochrane review: information provision for stroke patients and their caregivers . Clin Rehabil. 2009, 23:195-206. 10.1177/0269215508092820

14. Watkins CL, Leathley MJ, Chalmers C, et al.: Promoting stroke-specific education. Nurs Stand. 2012, 26:3540. 10.7748/ns2012.05.26.39.35.c9132

15. Coleman EA, Smith JD, Frank JC, et al.: Preparing patients and caregivers to participate in care delivered across settings: the care transitions intervention. J Am Geriatrics Soc. 2004, 1817:1825. 10.1111/j.15325415.2004.52504.x

16. Abdul Aziz AF, Mohd Nordin NA, Abd Aziz N, et al.: Care for post-stroke patients at Malaysian public health centres: self-reported practices of family medicine specialists. BMC Fam Pract. 2014, 15:40. 10.1186/14712296-15-40

17. Rahman S, Khair A, Salek M: Training of caregiver for home care management of stroke survivor at low resource setting. Bangabandhu Sheikh Mujib Medical University Journal. 2016, 9:193-195. 10.3329/bsmmuj.v9i4.30158

18. Kalra L, Evans A, Perez I, et al.: Training carers of stroke patients : randomised controlled trial . BMJ. 2004, 328:1-5. 10.1136/bmj.328.7448.1099

19. Yamane T: Statistics, An Introductory Analysis. Harper and Row, New York; 1967.

20. Tan C-E, Abdul Aziz AF, Hi M, et al.: Validation of the caregiving knowledge questionnaire-my: measuring knowledge regarding positioning and feeding among Malaysian informal caregivers of stroke patients. Indian J Palliat Care. 2018, 24:406-410. 10.4103/IJPC.IJPC_99_18

21. Coleman EA, Ground KL, Maul A: The Family Caregiver Activation in Transitions (FCAT) Tool: A new measure of family caregiver self-efficacy. Jt Comm J Qual Patient Saf. 2015, 41:502-507. 10.1097/01.JHQ.0000460118.60567.fe

22. Chatterton HJ, Pomeroy VM, Gratton J: Positioning for stroke patients: a survey of physiotherapists' aims and practices. Disabil Rehabil. 2001, 23:413-421. 10.1080/09638280010008825

23. Academy of Medicine Malaysia, Malaysian Society of Neurosciences, Ministry of Health Malaysia. : Clinical Practice Guidelines on the management of ischaemic stroke. Ministry of Health Malaysia, Kuala Lumpur; 2012. www.moh.gov.my/med/htm

24. Lee KW, Choi SJ, Kim SB, et al.: A survey of caregivers' knowledge about caring for stroke patients . Ann Rehabil Med. 2015, 39:800-815. 10.5535/arm.2015.39.5.800

25. Siew Mee Y, Bee H: A comparison study on nurses' and therapists' perception on the positioning of stroke patients in Singapore General Hospital. Int J Nurs Pract. 2007, 13:209-221. 10.1111/j.1440172X.2007.00630.X

26. Tay KCP, Seow CCD, Xiao C, et al.: Structured interviews examining the burden, coping, self-efficacy, and quality of life among family caregivers of persons with dementia in Singapore. Dementia. 2016, 15:204-220. $10.1177 / 1471301214522047$

27. Greenwood N, Mackenzie A, Cloud GC, et al.: Informal carers of stroke survivors - factors influencing carers: a systematic review of quantitative studies. Disabil Rehabil. 2008, 30:1329-1349. $10.1080 / 09638280701602178$

28. Molloy GJ, Johnston M, Johnston DW, et al.: Spousal caregiver confidence and recovery from ambulatory activity limitations in stroke survivors. Health Psychol. 2008, 27:286-90. 10.1037/0278-6133.27.2.286

29. Tatsumi H, Nakaaki S, Satoh M, et al.: Relationships among communication self-efficacy, communication burden, and the mental health of the families of persons with aphasia. J Stroke Cerebrovasc Dis. 2016, 25:197-205. 10.1016/j.jstrokecerebrovasdis.2015.09.018

30. Yeung S, Lui MH-L, Ross F, et al.: Family carers in stroke care: examining the relationship between problem- 


\section{Cureus}

solving, depression and general health. J Clin Nurs. 2007, 16:344-352. 10.1111/j.1365-2702.2005.01537.x 